\title{
The Developmental Impact of Reverse-Migration Separation on Low-Income Chinese-American Children-Provider Perspectives
}

\author{
Kenny Kwong \\ Graduate School of Social Work, Touro College, New York, NY, USA \\ Email: kam.kwong@touro.edu
}

How to cite this paper: Kwong, K. (2017) The Developmental Impact of Reverse-Migration Separation on Low-Income Chinese-American Children-Provider Perspectives. Open Journal of Social Sciences, $\mathbf{5}$, 146-165.

https://doi.org/10.4236/jss.2017.55011

Received: April 10, 2017

Accepted: May 13, 2017

Published: May 16, 2017

Copyright $\odot 2017$ by author and Scientific Research Publishing Inc.

This work is licensed under the Creative

Commons Attribution International

License (CC BY 4.0).

http://creativecommons.org/licenses/by/4.0/

\begin{abstract}
Family service professionals, child development providers, and school teachers who work with American-born Chinese children of reverse-migration face great challenges especially when the specific needs of these children and their immigrant families are unknown to them. This study explored the experiences and perspectives of service providers on the possible developmental impacts of reverse-migration separation on returning children of Chinese immigrant families in New York City. Focus groups and key informant interviews were conducted with 20 healthcare providers, school teachers, social workers, and child and family service practitioners. Thematic analysis approach was used to analyze and encode qualitative information and to discover patterns and themes. The analytical process consisted of data immersion, taking notes, sorting data into codes, and comparing the themes across interviews. Findings revealed specific themes that included: 1) provider's observations of child's attachment, health, learning, and behavioral issues; 2) provider's views concerning parenting methods, skills, and challenges; and 3) suggestions for support and resources for Chinese immigrant families. Implications for social policy, intervention services, and future research on this needy immigrant population were discussed. Knowledge derived from this study is instrumental in raising awareness, broadening knowledge base, and increasing effectiveness among service professionals who serve this population.
\end{abstract}

\section{Keywords}

Culture, Low Income Families, High Risk Families, Parenting, Intergenerational Caregiving 


\section{Introduction}

As the largest Asian group in New York City, the Chinese American population had grown from 458,586 in 2008 to 506,768 in 2011, at a rapid 10.5\% rate of increase, with the majority of them (71\%) being foreign born [1]. From 2000 to 2010, among the four largest racial and ethnic groups living in NYC, the Asian child population was the only group that showed citywide gains in population, growing by $16 \%$ and the Chinese-American child population increased by $23 \%$ [2]. In the past two decades, a unique and alarming phenomenon was occurred among Chinese immigrant families in NYC in which many of them have sent their American-born infants to China to be cared by relatives, and reunited with their children years later in the United States. A study of 219 Chinese immigrant pregnant women in NYC found that $57 \%$ of expectant parents planned on sending their babies back to China shortly after birth, and more than $90 \%$ of them planned for the child's return when their child reached 3 to 6 years of age [3]. The 2014 vital statistics of NYC shows that 9438 infants delivered that year were of Chinese ethnicity [4]. The growth of Chinese immigrant population would mean that there will be an increase number of American-born infants being sent back to China for care, resulting in prolonged separation with their parents during the early years of their life. It is important to find out what impact this prolonged separation has on parents and their children.

Family separation as a result of migration is not a new social phenomenon. Across ethnic groups, adult immigrants in search for economic opportunities often leave their family behind in their home country [5] [6] [7]. The experience of immigrants separating with their families has been well documented in the literature categorized by groups, such as Salvadorans [5], Mexicans [7], Caribbean [8], and Chinese [9]. Serial migration occurs when parents migrate to the new country first, and have their children sent for reunification at a later date [8]. The practice whereby Chinese immigrant parents send their newborns to the home country to be raised, and have their children returned to the U.S. when they reach school age is termed "reverse-migration separation" [3]. Reverse-migration separation is found to be prevalent in more recent Chinese immigrants from the Fujian Province [3] [10].

Part of the fastest-growing Chinese-American group in the U.S., many Fujianese immigrants enter this country through illegal means and owe large debts to those who arrange for their arrival [6]. Many of these immigrants arrived in the U.S. without extended families and generally work long hours in service industries for low wages without benefits [3]. From 2006 to 2010, unemployment rates for Chinese workers increased from $6.4 \%$ to $8.1 \%$ [2]. Fujianese immigrants face a stiff competition for manual labor in service industries and restaurants [6]. Other than low wage jobs, there are very few opportunities for these undocumented workers to find standard tax-paying jobs. Undocumented immigration status, not only adversely affects Fujianese immigrants in their employment and income, but also exacerbates the problem for them accessing child welfare, social services, and healthcare which in turn adversely affects their health and well- 
being [11] [12]. Because of fear of legal involvement, many of them avoid accessing valuable resources and programs essential to meet their family needs. Compared to those who have legal status, undocumented immigrants are subjected to significantly more exploitive work conditions, receive limited or no job benefits, and have fewer reliable social ties to fall back on [11]. These barriers to services among Chinese undocumented immigrants present tremendous challenges for healthcare and child service providers, teachers, social service workers, and policy makers who strive to address the specific needs of these families and their children.

For families with working parents, having children cared for by grandparents is a very common practice in China [13] and Asian communities in the U.S. [14]. Low-income Chinese immigrants without extended family are faced with the dilemma of whether to raise their children in the U.S. or have them sent back to home country to be raised. In case of the latter, the extended family in China would assume the responsibility of caring for the American-born infants. Many Chinese immigrant families used webcams regularly for communicating with their child and caretakers in China [10]. Despite their efforts to maintain some level of communication with caregivers (mostly grandparents), there are notable concerns associated with physical separation of parent and child. Reverse-migration separation which occurs in an early stage of parenthood and in the early life of the child can have an adverse effect on parent-child attachment, the psychological development of the children, and adjustment for parents [3] [9]. Studies have shown that maternal separation was associated with maternal depression as well as the children's future psychological and emotional development [15] [16]. Bowlby [17]'s classical attachment theory suggested that a child's anger and aggressive behavior can be attributed to separation and interrupted relationship between the child and the primary caregiver. Prolonged separation during the first five years of life was associated with lack of affection and persistent delinquency [18]. When a parent fails to meet the child's needs or the parent's presence to provide comfort or protection is inconsistent or lacking, the child's normal development is negatively affected. A recent study by Tornello et al. [19] also found that infants who spent frequent overnights away from their primary caretaker experienced greater attachment insecurity than those who consistently stayed with their primary caregiver. Of the limited number of studies done on Chinese immigrants in North America in the areas of parenting and child development, several showed that Chinese immigrant families who had prolonged parent-child separation experienced elevated risks of socio-emotional and behavioral problems in the child, as well as strained parent-child relationships [3] [9] [20].

The study by Beauchaine et al. [21] on child development and parenting education identified a number of social adversity factors that may impact on parent intervention outcomes. Social adversity factors include marital problems, maternal depression, socioeconomic disadvantage, poor social support, and negative life stresses. Parents who experience these social adversity factors and face chronic life stress tend to use harsh reactive parenting strategies and are less able 
to respond appropriately to their children's ever-changing development [22]. When parents reported high level of stress, children with more difficulties in social and emotional situations were found to have lower academic performance [23]. The study by Cheah, et al. [24] on Chinese immigrant mothers and their preschoolers found that when "parenting hassles were perceived to be high, mothers may be less able to utilize their psychological resources to engage in warm and responsive parenting, inductive reasoning, and support their child's autonomy development" (p. 318). Chinese immigrant parents who experienced higher level of parental stress had more parent-child conflicts and were more likely to engage in harsh discipline methods [25]. Children who experienced reverse-migration separation are at risk of "double jeopardy"-separation from their parents at infancy and having to adjust to parents who were emotional strangers with high stress in life [26]. The parents of prolonged separation have adjustment issues as 'new parents' themselves, and are more likely to use harsher discipline on their children, resulting in their children exhibiting poor behavioral and emotional adaptations [25] [27].

The researcher recently completed a qualitative study to explore the lived experiences of Chinese immigrant families that went through prolonged separation and reunification, and understand their attitudes, perceptions, and reactions to the separation and reunification process [10]. The present study used a qualitative research approach to understand the experiences and perspectives of service providers who worked with children of Chinese immigrant families that went through separation and faced challenges after reunification in the U.S. Focus groups and key informant interviews were conducted with 20 healthcare providers, school teachers, social workers, and child and family service practitioners. Service providers who work with these children often face great challenges especially when the specific needs of these children and their immigrant families are unknown to them. There was increased adjustment, depression, and attentional problems seen in the children upon initial reunification with parents [3].

To date, there is no systematic study that has explored the experiences of these service providers. This study is the first to elicit the experiences of these service providers and to gain better understanding from the perspectives of service providers on the possible developmental impacts of reverse-migration separation on returning children of Chinese immigrant families. The study also explored possible interventions, methods, services, or practical tools that service providers could use to help these vulnerable families. It is hoped that this research will add to the much needed knowledge and understanding on specific needs of Chinese immigrant families and lead to the development of critical policy questions and practical tools for child care, school, health and mental health providers to early identify the needs of these vulnerable families and strengthen their abilities to cope with these challenges.

\section{Methods}

This study used a qualitative approach to understand the participants' expe- 
riences as rigorously and detailed as possible and to identify concepts and themes that emerged from interview data [28]. Focus groups and key informant interviews were conducted with healthcare providers, school teachers, guidance counselors, social workers, as well as child welfare and family service practitioners to explore what impact prolonged separation may have on child's development and wellbeing of low income Chinese immigrant parents. Thematic analysis approach [29] was used to analyze and encode qualitative information and to discover patterns and develop themes. Codes, categories, and concepts were developed inductively from transcribed interview and focus group data.

\subsection{Interview Questionnaire}

An interview guide (see Appendix 1) was designed to include open-ended semi-structured questions and where necessary "probes" or follow-up questions were used to elicit responses and increase richness of responses [28]. Specific topics and questions covered in the guide include: provider's observations of child's attachment, health, learning, and behavioral issues, provider's views concerning parenting methods, skills, and challenges, and suggestions about intervention services, support, and resources for Chinese immigrant families to meet their specific concern and challenges. Prior to conducting the interview, each provider participant was asked to provide basic demographic information such as age, gender, type of profession, number of years of practice experience, and number of years working with low- income Chinese immigrant families. Each interview lasted for an hour. The Human Research Protection Program of Hunter College approved the study.

\subsection{Study Participants}

This study used a purposive sampling [28] to target service providers and helping professionals who have worked with Chinese immigrant families that went through prolonged separation and reunification. To recruit potential participants, in spring of 2014 the researcher distributed over 150 recruitment letters during major professional events and meetings hosted by NYC's social service organizations serving predominately Asian American communities. The study successfully recruited 20 service providers and completed 12 key informant interviews and two focus groups. To show appreciation for their participation, each participant received $\$ 40$ as a small gift whether he or she completed the individual or group interview or not. Every effort was made to ensure that participation in the study would be voluntary and that no participants should feel any pressure to participate in the study. All participants consented to be audiotaped; they were given pseudonyms to protect their identities. All interviews were conducted in English and then transcribed. Table 1 summarizes the demographic characteristics and service experiences of 20 participants. All participants were female. The average age was 39 years (range $=23-60$ ). The average number of years of practice experience was 11.25 years with a wide range from 1.5 to 25 years which also corresponded to a wide range of years of practice with Chinese 
Table 1. Background characteristics and service experiences of participants $(N=20)$.

\begin{tabular}{|c|c|c|c|c|c|c|}
\hline Field ID & Age & Gender & Profession & $\begin{array}{l}\text { Yrs in } \\
\text { field }\end{array}$ & Services the organization provides & $\begin{array}{c}\text { Years } \\
\text { working w/ } \\
\text { Chinese }\end{array}$ \\
\hline F1 & 23 & Female & Case Planner & 2 & $\begin{array}{l}\text { Preventative services, } \\
\text { home visits, and referrals }\end{array}$ & $1-5$ \\
\hline S1 & 29 & Female & Social Worker & 1.5 & $\begin{array}{l}\text { Case management } \\
\text { and care coordination }\end{array}$ & $1-5$ \\
\hline PC1 & 60 & Female & $\begin{array}{c}\text { Parent } \\
\text { Coordinator }\end{array}$ & 12 & $\begin{array}{l}\text { Liaise between school and parents; } \\
\text { work with parents }\end{array}$ & $11-15$ \\
\hline GC1 & 46 & Female & $\begin{array}{l}\text { Guidance } \\
\text { Counselor }\end{array}$ & 17 & $\begin{array}{l}\text { Help child adjust to school setting, } \\
\text { address misbehavior, work with } \\
\text { teachers with child's behaviors. }\end{array}$ & $16-20$ \\
\hline F2 & 24 & Female & $\begin{array}{l}\text { Family services } \\
\text { coordinator }\end{array}$ & $7-8$ & $\begin{array}{l}\text { Early childhood, youth, adult and } \\
\text { family, senior services. }\end{array}$ & $1-5$ \\
\hline S2 & 55 & Female & $\begin{array}{l}\text { Pediatric Social } \\
\text { Worker }\end{array}$ & 20 & $\begin{array}{l}\text { Comprehensive medical and mental } \\
\text { health hospital with outpatient clinics. }\end{array}$ & over 20 \\
\hline F3 & 35 & Female & $\begin{array}{l}\text { Program } \\
\text { Director }\end{array}$ & 12 & $\begin{array}{l}\text { Social services: home visits, classroom } \\
\text { experience for children } 0 \text { - } 5 \text { years old }\end{array}$ & $6-10$ \\
\hline S3 & 32 & Female & Social worker & 8 & $\begin{array}{l}\text { Senior housing, case management, } \\
\text { individual counseling, home visits. }\end{array}$ & $11-15$ \\
\hline S4 & 31 & Female & Social Worker & 7 & $\begin{array}{l}\text { Discharge planning, group therapy, } \\
\text { individual and family therapy }\end{array}$ & $6-10$ \\
\hline S5 & 27 & Female & Social Worker & 2 & $\begin{array}{l}\text { Mental health counseling, social } \\
\text { services, immigrant services }\end{array}$ & $1-5$ \\
\hline S6 & 35 & Female & Social Worker & 4 & Social Services \& mental health & $1-5$ \\
\hline P1 & 51 & Female & Pediatrician & 20 & Health Center Medical services & $16-20$ \\
\hline $\mathrm{T} 1$ & 39 & Female & Teacher & 15 & Elementary School & $16-20$ \\
\hline $\mathrm{T} 2$ & 35 & Female & Teacher & 8 & Elementary School & $11-15$ \\
\hline $\mathrm{T} 3$ & 45 & Female & ESL Teacher & 12 & Elementary School & $11-15$ \\
\hline $\mathrm{T} 4$ & 29 & Female & $\begin{array}{l}\text { Special Ed } \\
\text { Teacher }\end{array}$ & 3 & Elementary School & $1-5$ \\
\hline T5 & 55 & Female & ESL Teacher & 20 & Elementary School & over 20 \\
\hline $\mathrm{O} 1$ & 37 & Female & $\begin{array}{l}\text { Non-profit } \\
\text { management }\end{array}$ & 15 & $\begin{array}{l}\text { Policy, advocacy, research, capacity } \\
\text { building, financial help }\end{array}$ & $11-15$ \\
\hline $\mathrm{O} 2$ & 53 & Female & $\begin{array}{l}\text { Health Care } \\
\text { Admin }\end{array}$ & 25 & $\begin{array}{l}\text { Public Health, Human Services, } \\
\text { Community Engagement }\end{array}$ & over 20 \\
\hline P2 & 40 & Female & Pediatrician & 14 & Medical, mental health, social work & $11-15$ \\
\hline
\end{tabular}

immigrant families. Thirty percent of participants had worked with Chinese immigrant families within 1 to 5 years and $30 \%$ had more than 16 years. These participants have worked in diverse practice fields with different professional backgrounds including health and mental health, teaching, guidance counseling, social work, and child and family service administration and advocacy.

\subsection{Data Analysis}

Narrative data from individual interviews and focus groups was studied qualitatively using technical procedures based on the thematic analysis approach [29]. The analytical process consisted of data immersion, taking notes, and sorting data into codes and categories, and comparing the themes across interviews. The interview data was read and re-read to ensure the accuracy of developing an in- 
ductive code. ATLAS. ti, a qualitative analytical software program, was used to code and organize the data [30]. Open coding was used to scrutinize interview data's body of words, phrases, and sentences [31]. All transcript data, codes, categories, and quotations were reviewed for interconnection as well as relevance to the research questions. All these procedures were used to make the emerging concepts and themes denser and more precise as these concepts and themes were examined constantly and systematically within the data [31]. To enhance credibility and trustworthiness of study data [32], the researcher checked for representativeness of key findings as well as quotations used to illustrate the concepts and themes. In addition, the researcher also checked to see whether descriptions and emerging themes on the data were both accurate and complete.

\section{Results}

\subsection{Provider's Observation of Child's Attachment, Health, Learning \& Behavioral Issues}

\subsubsection{Attachment and Strained Family Relationships}

Several studies have shown that American-born children who were raised in China from infancy and reunited with their parents years later experienced adjustment and attachment issues upon their return [3] [9] [10]. Findings in this study concurred with previous studies on the subject. Provider participants observed that most parents did not have a close relationship with their children due to prolonged separation. Many American-born Chinese infants were sent back to China shortly after birth and returned to reunite with their parents when they reached 3 to 6 years of age [3]. A recent study found that the average age of the infant at the time of separation was 7.5 months. At the time of reunification, their average age was 4 years old. The average time during separation was 3.27 years [10]. A mental health social worker observed that even after these children returned to the U.S. and lived with the parents for a while, they still had problems bonding with their parents. It was hard for them to relate to their parents as parents. "When there is no attachment, the child lies to their parents and don't listen or respond... At home, the child shuts down and is not attached to the parent." In addition of having difficulties bonding and attaching with the parents, these children also had strained relationship with siblings who were raised by their parents in the U.S. Some of the children were resentful to siblings who were not sent to China. This contributed to jealousy and rivalry among the children. A social worker observed, "If some children in the same family were raised by their parents in the U.S., the child who was sent back and returned is more vulnerable to bullying by the sibling who was raised by the parents."

\subsubsection{Health Concerns}

Many of the Chinese families seen by provider participants in this study were unaware and unprepared for health related issues due to prolonged separation. A pediatrician who worked with Chinese immigrant families for more than 15 years summarized succinctly a wide range of health issues these children might 
have: prescriptions, access to preventive screening, breastfeeding, overfeeding, risk of obesity and overweight, and dental hygiene.

Breastfeeding is an issue because parents do not breastfeed the babies who will be sent back home shortly or else it'll be hard to stop lactation... When the child gets sick in China, the parents ask if we could give prescription to treat the child. We cannot do so. I am not even sure what the screening process is in China if the child has developmental delays. They may only treat the child for developmental delays after it becomes a medical problem... Grandparents spoil the grandchildren and they have trouble setting limits on what their grandchildren eat. If they allow the child to have a lot of fast food, it may lead to childhood obesity... Another big problem is a lack of preventive dental care in China. Kids from China come back with really bad cavities. Dentists [in China] don't talk to families about dental hygiene or flossing (P2).

In traditional Chinese culture, providing food is an expression of love. Grandparents in China tend to overfeed the grandchildren and this often results in poor eating habits, putting the children at risk of obesity. A health care administrator noted, "The child was spoiled by grandparents, were piggybacked, were allowed to eat whatever they wanted, and not disciplined in manners. Grandparents thought that giving the grandchild whatever they wanted was the best way to raise them."

\subsubsection{Learning, Language Development, and School Behaviors}

Children who were raised in China did not attend daycare or pre-schools in the U.S. They experienced a range of learning and educational challenges when they returned to the U.S. to attend elementary school. In this study, five teachers, one guidance counselor, and one parent coordinator who worked at an elementary school were interviewed. They reported that many of these children had the issues that include: 1) delays in learning; 2) delays in language development and expression; and 3) behavioral difficulties.

In China, children seemed to have "normal" language skills and when they came back to the United States, they became withdrawn...One could tell that the child had a lot of delays. Such delays are detected through assessing their language and behavior. There were also learning delays. When we could not read (understand) the child, we could not provide them with the right intervention. (F3)

If grandma were illiterate, she wouldn't see the need for the child to learn especially if the child is going back to America. So the opportunity for reading and language development in early childhood was lacking. If the grandparents could read, they could read to the child. Unfortunately in rural areas of China, childrearing means only feeding the child. (T5)

The child's ability to follow class routine and teacher instruction is crucial to learning and cognitive development. For these children, learning has been af- 
fected by their behavior in classroom settings. A guidance counselor noted that these children did not listen and were attention seeking and insecure. "The girl was very confused about who her parents were. She was angry and upset but was not able to express her feeling. She was emotional and did not listen to her parents. She felt insecure... If the child felt loved, she would listen to the parents... When the teachers asked the parents to teach the child proper behavior, the parents ask the teachers instead how to get the child listen to them." Because of difficulties in staying focused in class, they also exhibited social and emotional issues such as aggression, defiant behavior, or anxiety. One social worker commented, "A child separated from parents for a few years. The child came back crying. If the child had good language skills, the child could express his or her feeling. I had seen kids who were very aggressive... I also have seen kids who were very anxious, seemed lost, and did not know what was going on. When the plane arrived at JFK, the child said to the mom, 'Why am I here? This is not my home."' Some participants noted that children who returned lack self-care ability possibly because their grandparents spoiled them. A guidance counselor commented, "The child is not very independent after coming back... The child is self-centered and would wait for people to feed him. The teachers cannot cater to just one child."

\subsection{Provider's Views Concerning Parenting Methods, Skills, and Challenges}

\subsubsection{Parenting Methods and Difficulties}

Raising a child with unmet emotional needs, poor behavioral regulation and learning needs and in a stressful context such as poverty, parental stress, and limited social support may interfere with parents' abilities to respond in constructive ways to their children's ever-changing development [22] [27]. Provider participants in this study attributed part of parenting difficulties to the way these children were raised by grandparents in China and a lack of agreement between Chinese parents and the grandparents on child discipline issues. Many Chinese parents complained that grandparents in China often spoiled their children and did not share much information about the child or follow the requests of parents from the U.S. [10]. Participants in this study also observed that many of these immigrant parents were relatively young and inexperienced as a parent. They did not have adequate parenting skills. A case planner of a preventive service agency commented, "Parents do not recognize their child's developmental needs. They need to build a relationship with their children but they do not invest much time to foster the child's social and emotional development ...They may not notice that the child is not responding to them when they speak. They do not know these could be signs of developmental problems."

\subsubsection{Limited Knowledge of Child Development and Barriers in Accessing Resources}

Provider participants indicated that when Chinese immigrant parents experienced difficulties in child discipline, they tended to think that the problems 
lied in the child only. They were often unaware of how their own parenting methods might affect the child and what changes they could make to become effective parents. A social worker commented, "When parents sought counseling, they asked, 'What is wrong with my child?' They did not ask, 'What have I done wrong?' These parents focus on the child being the problem... they did not realize that they too needed to change and adjust...They only blamed the child for not cooperating." A guidance counselor shared her frustration when she worked with a parent on addressing the child's academic and behavioral issues, "A father bluntly said that it was the school's responsibility to take care of child during school hours and that he should not be bothered for any problems the child has in school." An administrator of a child advocacy agency commented that many parents did not recognize the importance of promoting child development, "I am not sure if parents know that early childhood development affects later development. This is not the topic being talked about in the Chinese culture." Another provider participant observed that Chinese parents tended to focus on physical needs of their children more than their social and emotional development. They also had limited knowledge of available social services and did not know how to access them when needed.

Many of these families were recent immigrants and they tended to be skeptical about seeking help for fear of revealing themselves and being "tracked by the government". A pediatrician commented, "We advise them to see social workers and seek help but there is a stigma to seeking services... Parents are also concerned about leaving a permanent record that can be tracked by the government. Sometimes it takes a year or two to persuade families to get services... In regards to home visits, they don't like the idea of someone coming to their house." This observation affirmed the finding from the literature that because of fear of legal involvement, many immigrants (especially undocumented) avoid accessing resources and services from government agencies [11] [12].

\subsection{Suggestions for Support and Resources for Chinese Immigrant Families}

While there is much child development literature on the effects of prolonged separation on attachment and psychological development of children, there are limited studies on what services these families need to help them adjust during the reunification period. Provider participants in this study had many years of practice experience working with Chinese immigrant families. Seventy percent of participants had worked with Chinese families for six years of more and were very knowledgeable about resources and support that was available for Chinese immigrant families. Some participants observed that Chinese parents often lived in overcrowded quarters and had harsh working conditions, which led to high stress level. They empathized that Chinese parents had guilt feelings toward their children who had adjustment issues upon their return to the U.S. A social service agency director commented, "When parents needed to address their child's behaviors, they felt very hopeless, helpless, and depressed. In parenting workshops, 
these parents did not want to share. If parents could not even meet their own needs, it would be hard for them to address the child's needs."

\subsubsection{Skills Training and Parent Engagement}

Provider participants were asked what services they thought would be helpful to parents and children who just reunited. They believed that these families would benefit from parenting skills workshops that addressed topics such as parent-child relationship, communication skills, and child development. A case planner of a child preventative service agency emphasized the needs of Chinese parents to rebuild their relationship with the child who just returned after prolonged family separation. Her employment agency offers parenting skills class for parents who have young children with specific needs and provides individual and family counseling to teach parents how to build positive relationship with children. A social worker with many years of practice experience in individual and family counseling suggested that Chinese parents should be consistent in disciplining the child and in setting limits. "They need to strike a balance between not being too lenient or too harsh. In addition to focusing on problems, they should also focus on the strengths of the child."

On the issues of parents focusing on the problems of the child but being unaware of their own inadequacy in parenting skills, engaging these parents in workshops and skills training activities to raise their awareness on underlying parent-child relationship issue is important. A social worker observed, "The more reluctant the parents are to change, the more difficult to change their mindset. What you see on the child is a reflection of the parents... These parents support their child by working really hard, but when the child exhibits behavioral problems, they ask, 'This is how you pay me back?' Parents blame the child for not cooperating with the family after the reunion. They said they made much sacrifice by sending their child away."

\subsubsection{Parenting Toolkit and Support}

A pediatrician pointed out that parenting tool kits with useful information to the parents might be helpful. "When the child reunited with his/her parents, the parents needed to bond with the child...It would be helpful if we could provide a parenting toolkit with practical tips to the parents. The parenting toolkit could include information on how to bond with the child who just returned, rebuilding relationship, safety issues, discipline, and limit setting." Other participants found parent support groups to be helpful especially for parents who were socially isolated. Support groups foster mutual support and peer counseling among these immigrant parents. A participant put it, "Support groups would be helpful as families could share their experiences and learn from each other and offer mutual support. We should continue to support these families who got their children back from China so that they can advise each other what to do."

\subsubsection{Concrete Services, Child Care, and Early Childhood Education}

Many Chinese immigrant families served by these providers shared a number of 
social adversity factors that might impact on parent-child relationship and parenting outcomes [21] [33]. These social adversity factors include socioeconomic disadvantage, poor social support, and negative life stress. Thus, provider participants in this study strongly suggested that more welfare assistance, concrete services, daycare, and early childhood services should be provided to these families to help them cope with their daily stress and specific challenges associated with raising their returning children. For example a parent coordinator who worked in an elementary school shared about her work to offer English classes specifically for these immigrant parents. She believed that if parents could learn and speak English, they could communicate better with the teachers and that their child could learn better. Many Chinese immigrant parents she served were poor and they asked her a lot of questions such as how to apply for government subsidized housing. Another participant who worked in a non-profit child advocacy agency discussed about the urgent needs to provide more childcare options for these families, "There is a lack of childcare options and we have yet to see how universal pre-k is rolling out. We also need family day care providers in the neighborhood and make sure that providers are well trained to ensure safety of the child."

A couple of participants indicted that early childhood education is essential and if possible reaching out to Chinese mothers during their pregnancy and providing them with information and resources on child development would be helpful for them.

We need to do more preventive work for pregnant moms... We ask families what they think is going to happen [after prolonged family separation]. The earlier we talk to these families about the pros and cons of sending children back to China the better. We can help parents understand how the child felt when they were sent away and prepare the parents on what adjustments to expect upon reunification. (F3)

Agencies can outreach to moms who are pregnant or have a young child and provide recommendation to these parents on child development. For example, children in China could be taught how to use fork and spoon so they might adapt quicker after reunification. If the child had attended school in China, it would be easier for the child to follow class routine and teacher instruction in the U.S. (GC1)

\section{Discussion}

The present study explored the experiences and perspectives of service providers who worked with returning children of Chinese immigrant families and assessed the possible developmental impacts of reverse-migration separation on these children. "These families have very little social and family support and are more comfortable with grandparents taking care of kids... For them, there are only "bad" options. Having your parents take care of your child is not the best option but better than hiring a babysitter." This comment from a social worker elucidates the fact that the choice Chinese immigrant parents made to be separated 
from their newborns is not entirely the "best" or "voluntary" decision. Kwong and $\mathrm{Yu}$ [10] found that many families voiced regret in not having their child with them in the U.S., but also clearly stated that they had "no choice" but to send their child to China; that having their child cared for by grandparents and relatives was the better option that they had.

As a significant segment of Chinese immigrant parents continue to practice reverse-migration separation, many American-born children of Chinese immigrants are not being raised by their birth parents during the formative years of his or her life. Service providers in this study reaffirmed a typical socio-demographic profile of the parents as suggested in the literature [3] [6]: they are relatively young, have low income, with limited child care services and family support available to them. Many have no legal status, work long hours, and have a stressful life. Duncan et al. [34] found that indicators of cumulative disadvantage in one's life situation have particularly strong effects when experienced in early childhood. Young childhood is a period when critical cognitive and social skills are developing; thus early intervention may make more of a difference than later in development [35]. At a time when other urban disadvantaged populations, with the help of early childhood intervention services, are trying to strengthen families and promote social cohesion, Chinese immigrant families that practice reverse-migration separation are heading the opposite direction. Their family ties threatened instead of strengthened; these immigrant families are trapped with a cycle of financial and emotional dilemmas.

Child care provided by grandparents for their grandchildren is a very common practice among Asian communities in the U.S. [14]. In the Chinese culture which is family-oriented, Chinese families feel more comfortable having grandparents as caregivers. However, this arrangement for the child to be raised by grandparents in China and subsequent reunification of the child and parents in the U.S. has potential adverse effects to psychosocial functioning and mental health of both the parent and the child involved [3] [9]. Information shared by mental health practitioners and social workers in this study affirmed these findings and provided insights into the possible effects of reverse-migration separation, such as the lack of parent-child attachment upon reunification, conflicting relationships between the parent and child, and rivalry between siblings who were raised by their parents versus ones who were sent back to China. Because of lack of bonding and attachment with parents, the child displayed a range of behavioral, relationship, and communication issues. Chinese parents recognized the benefits of having their children raised in China namely better child-care assistance and support, and retention of Chinese language and culture [3]. However, they also realized that there was a price associated with the prolonged parent-child separation, including poor parent-child relationship, attachment challenges, and socio-emotional and behavioral issues among the returning children [10]. Mental health clinicians in this study observed that these issues were further exacerbated by ineffective parenting method, parents' limited understanding of the child's socio-emotional needs, and their limited insights in their need to change themselves so as to become an effective parent. 
Pediatricians, teachers, and a guidance counselor included in this study had many years of experience working with Chinese immigrant families. They observed a range of other critical developmental issues related to or exacerbated by reverse-migration separation namely health concerns, learning, language development, and school behaviors. Interviews with this subgroup of provider participants showed that there seemed to be a link between their views of reverse-migration phenomenon and of their perceived role and how they responded to the needs and issues of returning children of Chinese immigrant families. They tended to focus primarily on medical, language, and learning needs of these returning children and shared much frustration about working with immigrant parents to address such needs. They appeared to show less understanding of the possible role of socioeconomic, cultural, or family related factors that might influence the reverse-migration practice of Chinese immigrant families. Because of such a narrow focus of a particular aspect of the child development, both the psychosocial and emotional needs of the child and the parent would be overlooked by these participants, or not seen as part of their role. Thus if these providers think their role is just within the medical or educational domain, they may fail to recognize the complex interaction between physical, cognitive, social, and emotional aspects of child development and are also less aware of the range of services that these children and parents need. It should be noted that service providers routinely deal with problems, issues, and challenges presented by Chinese immigrant families, thus they are more eager to discuss about problems and negative outcomes. Certainly not all Chinese immigrants will experience the negative consequences of reverse-migration separation nor encounter issues as noted by service providers. Understanding these immigrants' experiences from a strengths-based perspective will provide service providers with a wealth of information on how to work more successfully with these families at reunification. Recognizing and mobilizing family strengths and supporting their needs may help professionals develop more effective strategies to engage these vulnerable families to access immediate services and interventions.

\subsection{Implications for Policy, Services, and Research}

Findings in this study have several implications for social policy, intervention services, and future research of this hard-to-reach immigrant population. On the social policy change level, high quality and affordable child care services need to be made available to immigrant families so that they will not have the need to send their infants overseas for child care. The issue of affordable day care services may be addressed by linking community and economic planning with the needs of residents, with a focus of building more day care facilities within each community. Such efforts will require policy foresight, long-term planning, and committed investments in the health and wellbeing of immigrant populations. In 2011, an estimated 280,000 unauthorized immigrants living in the United States were from China [36] with the majority of them lived in the NYC metropolitan areas. Undocumented immigrants often faced employment exploitation 
because of their illegal status. A family and child service administrator commented, "Workers are exploited by employers. Replacement of workers is easy so immigrants fear to leave their jobs. If the government takes steps to address this issue, there will be less exploitation of immigrant workers... Making sure that they are paid a decent wage and given access to healthcare is important. This will alleviate some of the stress in their lives. I think sometimes people feel trapped in their situation and lose hope; we need to find ways to protect their rights even though they are undocumented." Poor employment conditions such as low income, multiple jobs, and long working hours caused these poor immigrant parents to be physically and emotionally unavailable to raise their own infants. Better employment opportunities with decent wage and work hours will provide these working parents with the needed stability to care for their children in the U.S. There are many undocumented Chinese immigrants living in fear of deportation [6]. Their undocumented immigration status exacerbates the problem for them accessing child welfare, social services, and healthcare which in turn adversely affects their health and well-being [11] [12]. Many avoid accessing valuable resources and programs essential to meet their family needs. Therefore, it is critically important for service providers to understand the unique life circumstances and stress of these immigrants within their social, economic, and cultural milieu and develop effective strategies to engage them in service delivery.

In terms of intervention services, provider participants in this study suggested that more programs such as concrete services, referrals for social services, and child care supports should be provided to these families. Different types of services would be helpful for Chinese immigrant families at different stages of the separation or reunification process. Informational sessions on preventive services and early childhood education will be particularly beneficial for pregnant women who are considering sending their child to China. For parents who have reunified with their children, parenting workshops and communication skills training will better prepare them for the challenges of adjustment. At the same time, counseling support to children and their parents should be made available to help families where children express any social, emotional, behavioral, language, or learning difficulties. Support groups will provide a forum for parents to share their experience and concerns with each other and to foster mutual support and learning.

As for areas for future research, while this study with service providers shed some light on a number of issues faced by families who practiced reverse-migration separation-a subject matter that was largely understudied-there still exists a need for more systematic studies employing longitudinal study designs and standardized measures. Such studies would help assess both short-term and long-term psychosocial and mental health outcomes on children who went through prolonged separation. Standardized tests and assessments could be employed to study psychosocial and mental health issues, and life stress experienced by these immigrant families. In-depth assessments of their child care, 
schooling, and health needs are needed to help develop intervention strategies that are appropriate for this population.

\subsection{Limitations}

There are a number of limitations to this study. First of all, the sample size used in the study was small. The small sample size means the findings of the study may not be generalizable to a large community of service providers who have worked with Chinese immigrant families that went through prolonged separation and reunification. Second, participants were self-selected to participate in the study. Although participants came from diverse professional backgrounds such as health and mental health, education and guidance, social work, child and family practice and advocacy, this sample is non-representative as the sampling design is meant to include the breadth of perspectives represented in diverse practice fields rather than aiming at generalizing to the larger population of service providers. These service providers contribute their valuable and distinct perspectives on this phenomenon. However, they may fail to recognize the underlying complex interrelated issues facing these immigrants who went through prolonged separation and reunification. In addition, data collected in this study was based solely on participants' opinions and their anecdotal observations of Chinese immigrant families who practice reverse-migration separation. The study did not employ any systematic or standardized clinical assessment tools. Therefore observations as reported by participants are not perceived as empirical evidence but rather their opinions and perception.

\section{Conclusions}

This study contributes to our knowledge of reverse-migration separation, a common practice among a vulnerable, hard-to-reach immigrant population. It sheds light on specific needs of Chinese immigrant families who have to send their child to China to be raised while parents work in the U.S. By studying closely the unique circumstances pertaining to prolonged separation, parenting practice, and related family challenges (low income, parental stress, lack of social support), preventive measures can be developed to promote and safeguard the overall wellbeing of the parent and the child. In addition, understanding these immigrant experiences from a strength-based perspectives and what coping strategies these families used to deal with life challenges helps practitioners recognize what the clients' service needs are and how to work more successfully with these families at reunification. In conclusion, knowledge derived from this study is instrumental in raising awareness, broadening knowledge base, and increasing effectiveness among family service professionals who serve this client population.

\section{Acknowledgements}

The author whole heartedly thanks all provider participants for their time and their openness in sharing their perspectives and professional experiences on the 
study phenomenon. The author particularly wants to thank Qing Yu Yu for her valuable support and help in completing this study. The study was funded by the PSC-CUNY Research Award Program and supported by Touro College Graduate School of Social Work.

\section{References}

[1] Asian American Federation (2013) Profile of New York City's Chinese Americans: 2013 Edition. Asian American Federation Census Information Center, New York. http://www.aafederation.org/cic/briefs/chinese2013.pdf

[2] Asian American Federation (2012) Asian Americans in New York City: A Decade of Dynamic Change 2000-2010. New York. http://www.aafny.org/pdf/AAF_nyc2010report.pdf

[3] Kwong, K., Chung, H., Sun, L., Chou, J. and Taylor-Shih, A. (2009) Factors Associated with Reverse-Migration Separation among a Cohort of Low-Income Chinese Immigrant Families in New York City. Social Work in Health Care, 48, 348-359. https://doi.org/10.1080/00981380802599174

[4] New York City Department of Health \& Mental Hygiene (2016) Summary of Vital Statistics 2014, the City of New York. http://www1.nyc.gov/assets/doh/downloads/pdf/vs/2014sum.pdf

[5] Abrego, L.J. (2014) Sacrificing Families: Navigating Laws, Labor and Love across Borders. Stanford University Press, Stanford.

[6] Chen, F. (2013) Fujianese Immigrants Fuel Growth, Changes. Voices of NY. http://voicesofny.org/2013/06/fuzhou-immigrants-fuel-growth-changes-in-chinesecommunity/

[7] Dreby, J. (2012) The Burden of Deportation on Children in Mexican Immigrant Families. Journal of Marriage and Family, 74, 829-845.

https://doi.org/10.1111/j.1741-3737.2012.00989.x

[8] Smith, A., Lalonde, R.N. and Johnson, S. (2004) Serial Migration and Its Implications for the Parent-Child Relationship: A Retrospective Analysis of the Experiences of the Children of Caribbean Immigrants. Cultural Diversity and Ethnic Minority Psychology, 10, 107-122. https://doi.org/10.1037/1099-9809.10.2.107

[9] Bohr, Y. and Tse, C. (2009) Satellite Babies in Transnational Families: A Study of Parents' Decision to Separate from their Infants. Infant Mental Health Journal, 30, 265-286. https://doi.org/10.1002/imhj.20214

[10] Kwong, K. and Yu, Q.Y. (2017) Prolonged Separation and Reunification among Chinese Immigrant Children and Families: An Exploratory Study. Journal of Child and Family Studies. https://doi:10.1007/s10826-017-0745-1

[11] Enriquez, L.E. (2015) Multigenerational Punishment: Shared Experiences of Undocumented Immigration Status within Mixed-Status Families. Journal of Marriage and Family, 77, 939-953. https://doi.org/10.1111/jomf.12196

[12] Yoshikawa, H. (2012) Immigrants Raising Citizens: Undocumented Parents and their Young Children. Russell Sage Foundation, New York.

[13] Chu, C.Y.C., Xie, Y. and Yu, R.R. (2011) Coresidence with Elderly Parents: A Comparative Study of Southeast China and Taiwan. Journal of Marriage and Family, 73, 120-135. https://doi.org/10.1111/j.1741-3737.2010.00793.x

[14] Asian American Federation (2014) The State of Asian American Children. New York. http://www.aafederation.org/doc/AAF_StateofAsianAmericanChildren.pdf

[15] Mäki, P., Hakko, H., Joukamaa, M., Läärä, E., Isohanni, M. and Veijola, J. (2003) 
Parental Separation at Birth and Criminal Behavior in Adulthood: A Long-Term Follow-Up of the Finnish Christmas Seal Home Children. Social Psychiatry \& Psychiatric Epidemiology, 38, 354-359. https://doi.org/10.1007/s00127-003-0642-3

[16] Miranda, J., Siddique, J., Der-Martirosian, C. and Belin, T. (2005) Depression among Latina Immigrant Mothers Separated from their Children. Psychiatric Services, 5, 717-720. https://doi.org/10.1176/appi.ps.56.6.717

[17] Bowlby, J. (1976) Attachment and Loss, Volume II, Separation: Anxiety and Anger. Basic Books, New York.

[18] Bowlby, J., Frey, M. and Ainsworth, M.D.S. (1953) Child Care and the Growth of Love. Penguin Books, London.

[19] Tornello, S.L., Emery, R., Rowen, J., Potter, D., Ocker, B. and Xu, Y. (2013) Overnight Custody Arrangements, Attachment and Adjustment among Very Young Children. Journal of Marriage and Family, 75, 871-885. https://doi.org/10.1111/jomf.12045

[20] Bernstein, N. (2009) Chinese-American Children Sent to Live with Kin Abroad Face a Tough Return. New York Times. http://www.nytimes.com/2009/07/24/nyregion/24chinese.html

[21] Beauchaine, T.P., Webster-Stratton, C. and Reid, M.J. (2005) Mediators, Moderators and Predictors of One-Year Outcomes among Children Treated for Early-Onset Conduct Problems: A Latent Growth Curve Analysis. Journal of Consulting and Clinical Psychology, 73, 371-388.

https://doi.org/10.1037/0022-006X.73.3.371

[22] Deater-Deckard, K. (2005) Parenting Stress and Children's Development: Introduction to the Special Issue. Infant \& Child Development, 14, 111-115. https://doi.org/10.1002/icd.383

[23] Soltis, K., Davidson, T.M., Moreland, A., Felton, J. and Dumas, J.E. (2013) Associations among Parental Stress, Child Competence and School-Readiness: Findings from the PACE Study. Journal of Child and Family Studies, 24, 649-657. https://doi.org/10.1007/s10826-013-9875-2

[24] Cheah, C.S.L., Leung, C.Y.Y., Tahseen, M. and Schultz, D. (2009) Authoritative Parenting among Immigrant Chinese Mothers of Preschoolers. Journal of Family Psychology, 23,311-320. https://doi.org/10.1037/a0015076

[25] Liu, S.W. (2014) Parental Stress, Acculturation and Parenting Behaviors among Chinese Immigrant Parents in New York City (Doctoral Dissertation). ProQuest LLC., 3620826.

[26] Valtolina, G.G. and Colombo, C. (2012) Psychological Well-Being, Family Relations and Developmental Issues of Children Left Behind. Psychological Reports, 111, 905 928. https://doi.org/10.2466/21.10.17.PR0.111.6.905-928

[27] Yates, T.M., Obradovic, J. and Egeland, B. (2010) Transactional Relations across Contextual Strain Parenting Quality and Early Childhood Regulation and Adaptation in a High-Risk Sample. Development and Psychopathology, 22, 539-555. https://doi.org/10.1017/S095457941000026X

[28] Patton, M. (2014) Qualitative Research and Evaluation Methods. 4th Edition, Sage, Thousand Oaks.

[29] Boyatzis, R.E. (1998) Transforming Qualitative Information: Thematic Analysis and Code Development. Sage Publications, Thousand Oaks, London and New Delhi.

[30] Friese, S. (2014) Qualitative Data Analysis with ATLAS. 2nd Edition, Sage Publications, Thousand Oaks.

[31] Grinnell, R.M. and Unrau, Y.A. (2013) Social Work Research and Evaluation: 
Foundations of Evidence-Based Practice. 10th Edition, Oxford University Press, New York.

[32] Yin, R. (2014) Case Study Research: Design and Methods. 5th Edition, Sage, Thousand Oaks.

[33] McInTyre, L.L. and Phaneuf, L.K. (2008) A Three-Tier Model of Parent Education in Early Childhood Applying a Problem-Solving Model. Topics in Early Childhood Special Education, 27, 214-222. https://doi.org/10.1177/0271121407311239

[34] Duncan, G., Ziol-Guest, K. and Kalil, A. (2010) Early Childhood Poverty and Adult Attainment, Behavior and Health. Child Development, 81, 292-311. https://doi.org/10.1177/0271121407311239

[35] Cunha, F. and Heckman, J. (2007) The Technology of Skill Formation. American Economic Review, 97, 31-47. https://doi.org/10.1257/aer.97.2.31

[36] Hoefer, M., Rytina, C. and Baker, B.C. (2010) Estimates of the Unauthorized Immigrant Population Residing in the United States. U.S. Department of Homeland Security, Washington DC. 


\section{Appendix 1}

Interview guide.

1. Is there a typical socio-demographic profile you have observed to exist among families who separate and reunite? Is the demographic profile we have gathered in the literature consistent with your own experiences working with the community?

2. What do you think are the driving factors motivating or impacting immigrant families to send their children to be raised in China?

3. Do you think the practice is encouraged or discouraged within the immigrant community?

4. What is your perception of the impact of separation on the family? How do families cope with not seeing their child, and what kind of problems do they encounter during separation? What do you think families expect of the experience of separation? Are their expectations accurate?

5. What observations have you made regarding children's adjustment to reunification?

6. What have you observed about the reunification process/impact of reunification on families?

7. What have you observed about the resources, support, resiliency, and methods used by these families to cope with the impact of separation and reunification?

8. What are your recommendations regarding health, mental health, education, and social services targeting these vulnerable families?

9. What information regarding this topic would be useful to you, as professionals working with this community that could be explored as an area for future research?

Submit or recommend next manuscript to SCIRP and we will provide best service for you:

Accepting pre-submission inquiries through Email, Facebook, LinkedIn, Twitter, etc. A wide selection of journals (inclusive of 9 subjects, more than 200 journals) Providing 24-hour high-quality service

User-friendly online submission system

Fair and swift peer-review system

Efficient typesetting and proofreading procedure

Display of the result of downloads and visits, as well as the number of cited articles Maximum dissemination of your research work

Submit your manuscript at: http://papersubmission.scirp.org/

Or contact jss@scirp.org 